\title{
Safety net applications in developing countries: Turkey and Iran case study
}

\author{
Gözde Tantekin Çelik ${ }^{1}$ (D), Serkan Aydınlı² ${ }^{*}$, Siamak Bazaati ${ }^{3}$ (D) \\ ${ }^{1}$ Cukurova University, Faculty of Engineering, Dept. of Civil Engineering, Adana, Turkey \\ ${ }^{2}$ Cukurova University, Ceyhan Engineering Faculty, Dept. of Civil Eng., Adana, Turkey \\ ${ }^{3}$ Osveh Institute of Higher Education, Faculty of Engineering, Dept. Of Civil Eng., Tabriz, Iran
}

\begin{abstract}
In this study, safety net applications, which are used as a collective protection measure in high-rise building constructions, in small and medium sized enterprises were investigated. For this purpose, safety net inspection form has implemented to building construction sites in Turkey and Iran. Study is focused on not only the presence of safety measures, but also the importance of correct application. In addition, it is aimed to draw attention to both the failures in the safety net applications and the general approaches to the Occupational Health and Safety (OHS) measures and awareness levels of the practitioners. Results show that there are many shortcomings in the safety nets in construction sites. The prominent shortcomings are determined as testing and labeling of safety nets. Moreover, factors that reduce the effectiveness of the safety net are observed frequently. The level of deficiencies varies by the level of detail of legal regulations and standards in the country. This paper makes important contributions to research field on the effectiveness of working at height measures.
\end{abstract}

\section{Keywords}

Construction industry; Occupational health and safety; Safety nets applications; Safety culture; Developing countries

Received: 06 January 2021; Accepted: 04 March 2021

ISSN: 2630-5771 (online) (C) 2021 Golden Light Publishing All rights reserved.

\section{Introduction}

Construction industry, one of the leading industries in developing countries, is leader in occupational accidents and occupational diseases statistics. According to Eurostat data, 682 fatal accidents occurred in the construction industry in 2018 [1]. Similarly, according to work accident statistics published by Repuclic of Turkey Ministry of Family, Labour and Social Services, Turkish construction industry ranks 4 th in all industries [2]. In same report, it is determined that fatal accidents rate in the construction industry is in second place after the mining industry. In Turkey, the most important reasons for the occupational accidents in the construction industry are; organizational climate, working at height, unsafe supervision, hazardous environment and safety culture $[3,4]$. Studies on occupational accidents and occupational diseases have shown that there is an inverse relationship between mortal accidents and human development index, and fatal occupational accidents are higher in countries with low human development index $[5,6]$. This affects safety culture

* Corresponding author

Email: saydinli@cu.edu.tr 
and climate especially in small and medium sized enterprises. High fatal accident rates in developing countries indicate that the OHS culture has not yet been fully adopted [7]. Altough legislation enacted in recent years, obligation of OHS training at undergraduate level and tightening of the inspections have positive effect on the occupational accident statistics in the construction sector, it has not reached a sufficient level yet compared to developed countries [7,8].

In the construction sector, the first reason of the work accidents is "falling from the height" [7,913]. Accidents caused by falling from height are followed by struck by thrown and projected or falling object accidents $[7,8,14,15]$. The accident types of falling from height are; falls from scaffold; falls from floor slab or platform edges; falls from floor and elevator openings and falls from roofs and other falls [8]. Accidents caused by falling from buildings may effected by many reasons such as building height, wind speed, employees' attitudes and risky activities $[16,17]$ and it is determined as the most dangerous accident type [7,17]. $47.5 \%$ of the occupational accidents occurred in the Turkish construction sector are due to worker or material fall [10]. On the other hand, this rate is $80.3 \%$ in Iran [18]. Besides, literature findings show that the major causes of injury or death are non-used or improper/damaged fall protection [19]. Thus, contractors should pay more attention to measures of OHS.

The most frequently used precautions for fall accidents are; the use of personal protective equipments (PPE), railings and safety nets. As stated in hierarchy of control measures for fall from height (FFH); If there is no restriction on implementation, collective protection measures are recommended rather than PPE usage. Among the collective protection measures, safety nets are used to protect workers in case of falling from a height, and also prevent objects from falling from high $[20,21]$. In addition, it is highly preferred in highrise buildings due to easy application and low cost [22].

In this study, safety nets applications in small and medium sized companies were analyzed and the problems experienced in the application were investigated. Two countries, Turkey and Iran, with intense work-related accidents in the construction industry are preferred [23-25]. Safety net applications used in Turkey and Iran were analyzed and the results were presented.

\section{Literature review}

\subsection{Prevention of fall from hight in construction industry}

It is known that protection measures are of vital importance for avoiding falling from height [26]. Non-use of protective equipment in work in height causes serious injuries and fatal accidents [27].

There is a hierarchy of control measures for $\mathrm{FFH}$, ranging from elimination (e.g., prefabricating wall frames horizontally before standing them up), substitution (e.g., using mobile elevated work platform instead of ladders), engineering controls (e.g., guardrails), administrative controls (e.g., working-at-height rules and procedures), to PPE (Fig. 1). Although the hierarchy considers PPE as the least effective control measure, it is a must in situations where working conditions are difficult and other controls are not applicable [28].

Apart from the hierarchical structure above, there are two types of protection measures which are primary and secondary measures against the risk of falling from height. While primary fall protection measures prevent falls, secondary protection measures save lives and/or reduce the impact of a fall [20].

Personal fall arrest equipments and collective fall arrest systems are two main precautions used in construction industry. The most common protection systems are safety lines and safety nets. Dong et al., [29] investigated personal fall arrest systems used in construction industry. Authors observed that no personal fall arrest systems are used especially in residential building sites. Chi et al., [20] investigated fatal occupational falls in construction industry and they associated accidents with measures. Authors concluded that safety nets can be implemented especially for scaffolding works and work at height. 


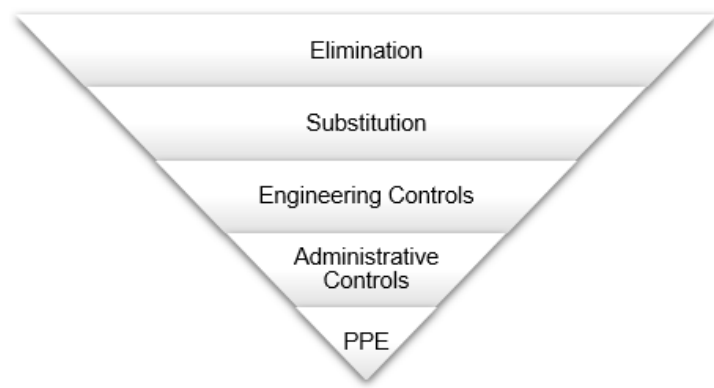

Fig. 1. Hierarchy of control measures for FFH

Adam et al., [22] studied the most frequently used fall-protection systems and the results show that the most frequently used system is safety nets because of easy installation and low cost. However, literature show that protective equipments are not considered necessary. Kines [27] studied fatal fall accidents in construction industry and author determined that safety nets are used only in 3 of 20 sites in which accident occurred. Literature findings show that arrest system of fall from height in construction industry is the vital factor for prevention of work accidents and fatal accidents.

\subsection{Requirements of safety net applications}

Safety nets are commonly used as secondary and collective protection measure, especially in highrise building sites. It is thought that approximately $87 \%$ of falls from height can be prevented by safety nets [20]. Safety nets are preferred due to their low costs, easy implementation and comfortable working condition [22]. Safety nets, installed under the working area, are used to reduce the falling distance of employees and to mitigate the effect of falling (Fig. 2). Three main issues that need to be considered in the safety net implementation are summarized below [30]:

- The safety net should comply with the standards specified in the legislation.

- It should be installed and dismantled according to standards by the expert team.

- Storage, maintenance and inspection works must be carried out periodically by qualified experts in accordance with the manufacturer's instructions.

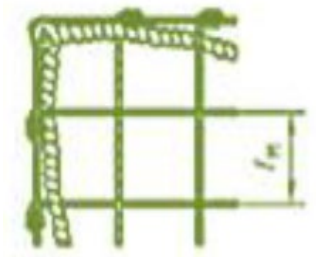

a) S type

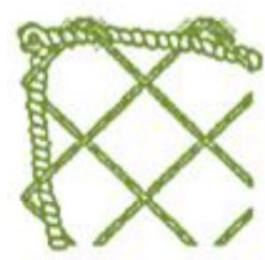

c) S type

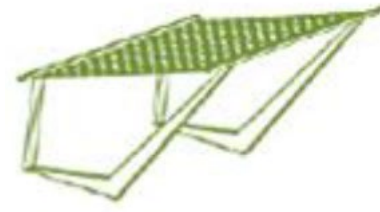

b) T type

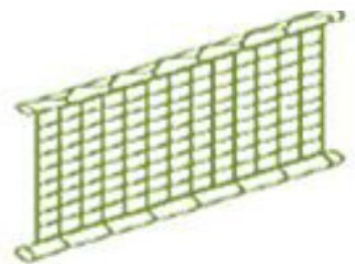

d) U type

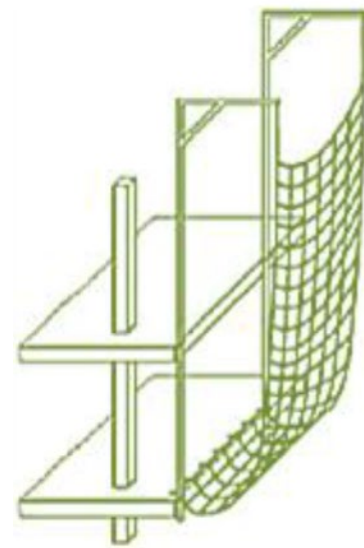

e) V type

Fig. 2. Safety net systems [30]

Safety nets, which are not installed in accordance with the above conditions, will not be able to perform their functions properly and will not be able to adequately protect the employee in the event of a fall.

Literature show that major factors, in order to ensure the effectiveness of safety nets are; compliance with the standards, selection of suitable materials, installation of the nets and detection of ripped nets. Especially, errors during installation, damages on the net, sharp and heavy items are factors reducing the efficiency of the safety nets. Therefore, the correct implementation of safety nets is of vital importance for falls from height accidents. 
Several national and international standards regulate the application of safety nets in construction sites. One of the widely used international standards is OSHA 29 CFR 1926.105 and national safety net standard used in Turkey is TS EN 1263-1-2. Although there is no detailed standard, legal regulations that provide guidance for occupational health and safety measures are applied in Iran. These regulations are "National Building Regulation", "Occupational Safety Regulations at Height" and "Safety Management at Construction Sites". These regulations are not focus on detailed applications but contain general explanations. According to National Building Regulation, it is necessary to take precautions against falling from height against all gaps in the construction site. Moreover, inspection details and metric information on the capture distances of safety nets are also included.

OSHA 29 CFR 1926 published in 1994 by Occupational Health and Safety Administration (OSHA) and regulates general standards of safety net applications. According to this standard;

- Safety nets shall be provided when workplaces are more than 7,62 meters above the ground.

- Where safety net protection is required, operations shall not be undertaken until the net is in place and has been tested.

- Nets shall extend 2,43 meters beyond the edge of the work surface.

- Attaching net panels shall develop the full strength of the net.

It is seen that while OHSA standard regulates the general concepts of safety net application, TS EN 1263-1-2, a national standard published in 2005 in Turkey, regulates standards of safety net applications by safety net types. According to TS EN 1263-1-2, there are four types of safety net which are $\mathrm{S}, \mathrm{T}, \mathrm{U}$ and $\mathrm{V}$ type. The standard describes all limit values such as fall height, net width and height of all types of safety net application. In this study, safety net implementation observations made in Turkey are evaluated according to the limits in this standard. Other studies focused on safety net applications like Peşan [31] gave an example of a safety net installation design and pointed out the details that should be considered during installation. Specifically, it is expressed that the nets should be overlapped where required. Uzun and Yaman [32] stated that safety nets should be designed by considering the architectural features, project-specific conditions, environmental conditions and climate data at the design phase. It is emphasized that safety nets in high-rise buildings are not taken to production level and should be leveled up by expert team in accordance with concrete casting programs. Dursun [33] examined the safety net applications in Turkey. As a result of the study, it was determined that the level of technical knowledge on safety net practices is not sufficient. Besides, the nets do not comply with the standards. There is no test mesh and it prevents nets from being tested for environmental factors.

In this study, it is aimed that the shortcomings of the safety nets used in building constructions are investigated and suggestions are made for the fall accidents.

\section{Methodology}

This paper investigates safety net applications in small and medium sized companies in two developing countries, Turkey and Iran. The sample of the study consists of high-rise building constructions using safety nets. At the end of the negotiations with construction professionals, safety nets at 44 construction sites in Turkey and 26 construction sites in Iran are investigated and the safety net checklists were filled. The checklist used in the study was taken from Dursun's [33] study. Safety nets were evaluated in terms of two main criteria. These criteria consist of factors that can directly affect the performance of the safety net at the time of the fall (deformations in the nets and supporting frame, strength of anchorage points, etc.) and factors that do not directly affect the performance of the safety net (information labels or features, etc.). The observations were made together with the representative of the researcher team and the technical staff in charge of the site. The checklist results were presented by frequency. 
In addition, observations on the occupational safety climate and culture at the sites are presented.

\section{Findings}

Safety nets have observed and filled the safety net checklist. The general characteristics of the safety nets used in construction sites are given in Table 1. It is seen that T-type safety nets were applied in all the construction sites in Turkey and 19 of the 26 sites in Iran. V type nets were applied in 5 sites and 1 site applied U type. In Turkey, safety nets are generally knotted with rhombus nets. On the other hand, it has been observed that rhombus (D) and knotless nets are generally used in construction sites in Iran. Interestingly, practitioners usually prefer covers instead of nets. It is clearly observed that the nets or covers used in Iran do not meet the standards and they are composed of unqualified fabrics and/or linens with inadequate stretching and bearing capacity. $70 \%$ of safety nets in Turkey were installed by an expert team. But in Iran, most of safety nets were installed by the unskilled workers of the contractor. Installation by unskilled workers may cause serious accidents due to incomplete or incorrect installation.
The results of the inspection of the safety nets are given in Table 2. The findings are as follows:

- The safety net user manual should be delivered to the users by the installation company and this manual should be kept on site. The user guide does not available in three fourth $(75 \%)$ in Turkey and most of Iran (57,69\%).

- The label that includes information such as brand name, manufacturer name, net specifications, manufacturing date and minimum energy absorption capacity of the test sample should be provided. In Turkey, one fourth $(25 \%)$ nets have no label or label can not be read, while in Iran, nets $(73,08 \%)$ have no label generally.

- Nets should be tested every 12 months in order to determine if there is any abrasion due to UV rays. For this purpose, at least 3 test meshs must be available. Nearly half of the safety nets in Turkey $(47,73 \%)$ have no test mesh. Moreover, it was seen that many chargehands did not know what the test mesh is. There is no label indicating UV tests in nearly half of the nets in Turkey $(45,45 \%)$ and majorty in Iran $(84,62 \%)$.

Table 1. General characteristics of safety networks

\begin{tabular}{|c|c|c|c|c|c|c|c|c|c|c|c|}
\hline & Characteristics & \multicolumn{4}{|c|}{ Turkey } & \multicolumn{6}{|c|}{ Iran } \\
\hline \multirow{3}{*}{1} & \multirow{3}{*}{ Type of safety net } & \multicolumn{4}{|c|}{$\mathrm{T}$} & \multicolumn{2}{|c|}{$\mathrm{T}$} & \multicolumn{2}{|c|}{$\mathrm{V}$} & \multicolumn{2}{|c|}{$\mathrm{U}$} \\
\hline & & \multicolumn{2}{|c|}{$\mathrm{n}$} & \multicolumn{2}{|c|}{$\%$} & $\mathrm{n}$ & $\%$ & $\mathrm{n}$ & $\%$ & $\mathrm{n}$ & $\%$ \\
\hline & & \multicolumn{2}{|c|}{44} & \multicolumn{2}{|c|}{100} & 19 & 73,08 & 5 & 19,23 & 1 & 3,85 \\
\hline \multirow{3}{*}{2} & \multirow{3}{*}{$\begin{array}{l}\text { Geometric shape of } \\
\text { the mesh }\end{array}$} & \multicolumn{2}{|c|}{$\mathrm{D}$} & \multicolumn{2}{|c|}{ Q } & \multicolumn{2}{|c|}{$\mathrm{D}$} & \multicolumn{2}{|c|}{ Q } & \multicolumn{2}{|c|}{ Cover } \\
\hline & & $\mathrm{n}$ & $\%$ & $\mathrm{n}$ & $\%$ & $\mathrm{n}$ & $\%$ & $\mathrm{n}$ & $\%$ & $\mathrm{n}$ & $\%$ \\
\hline & & 41 & 93,18 & 3 & 6,82 & 13 & 50,00 & 9 & 34,62 & 4 & 15,38 \\
\hline \multirow{3}{*}{3} & \multirow{3}{*}{ Type of mesh } & \multicolumn{2}{|c|}{ Knotted } & \multicolumn{2}{|c|}{ Knotless } & \multicolumn{2}{|c|}{ Knotted } & \multicolumn{2}{|c|}{ Knotless } & \multicolumn{2}{|c|}{ Cover } \\
\hline & & $\mathrm{n}$ & $\%$ & $\mathrm{n}$ & $\%$ & $\mathrm{n}$ & $\%$ & $\mathrm{n}$ & $\%$ & $\mathrm{n}$ & $\%$ \\
\hline & & 31 & 70,45 & 13 & 29,55 & 5 & 19,23 & 19 & 73,08 & 8 & 30,77 \\
\hline \multirow{3}{*}{4} & \multirow{3}{*}{ Installation team } & \multicolumn{2}{|c|}{ Expert Team } & \multicolumn{2}{|c|}{ Workers } & \multicolumn{3}{|c|}{ Expert Team } & \multicolumn{3}{|c|}{ Workers } \\
\hline & & $\mathrm{n}$ & $\%$ & $\mathrm{n}$ & $\%$ & $n$ & & $\%$ & $\mathrm{n}$ & & $\%$ \\
\hline & & 31 & 70,45 & 13 & 29,55 & 3 & & 11,5 & 23 & & 88,5 \\
\hline
\end{tabular}


Table 2. Safety net checklist results

\begin{tabular}{|c|c|c|c|c|c|c|c|c|c|}
\hline \multirow{3}{*}{ No } & \multirow{3}{*}{ Standards } & \multicolumn{4}{|c|}{ Turkey } & \multicolumn{4}{|c|}{ Iran } \\
\hline & & \multicolumn{2}{|c|}{ Yes } & \multicolumn{2}{|c|}{ No } & \multicolumn{2}{|c|}{ Yes } & \multicolumn{2}{|c|}{ No } \\
\hline & & $\mathrm{n}$ & $\%$ & $\mathrm{n}$ & $\%$ & $\mathrm{n}$ & $\%$ & $\mathrm{n}$ & $\%$ \\
\hline 1 & $\begin{array}{l}\text { Is the safety net operating manual available } \\
\text { at site? }\end{array}$ & 33 & 75,00 & 11 & 25,00 & 11 & 42,31 & 15 & 57,69 \\
\hline 2 & Are the nets properly tagged? & 33 & 75,00 & 11 & 25,00 & 7 & 26,92 & 19 & 73,08 \\
\hline 3 & $\begin{array}{l}\text { Is the manufacturer or importer's name } \\
\text { readable on the safety net? }\end{array}$ & 33 & 75,00 & 11 & 25,00 & 5 & 19,23 & 21 & 80,77 \\
\hline 4 & $\begin{array}{l}\text { Does the safety net label include information } \\
\text { when the net was manufactured? }\end{array}$ & 32 & 72,73 & 12 & 27,27 & 4 & 15,38 & 22 & 84,62 \\
\hline 5 & $\begin{array}{l}\text { Did the manufacturer or importer company } \\
\text { provide at least one test mesh with the safety } \\
\text { net? (One experiment mesh consists of at } \\
\text { least } 3 \text { meshs.) }\end{array}$ & 23 & 52,27 & 21 & 47,73 & 4 & 15,38 & 22 & 84,62 \\
\hline 6 & $\begin{array}{l}\text { No deformation in the nets or supporting } \\
\text { frame. }\end{array}$ & 34 & 77,27 & 10 & 22,73 & 7 & 26,92 & 19 & 73,08 \\
\hline 7 & $\begin{array}{l}\text { Are all ropes used in safety nets securely tied } \\
\text { to prevent disassembly? }\end{array}$ & 37 & 84,09 & 7 & 15,91 & 8 & 30,77 & 18 & 69,23 \\
\hline 8 & $\begin{array}{l}\text { The net was not previously used to stop a fall } \\
\text { or any load that would cause permanent } \\
\text { deformation. }\end{array}$ & 28 & 63,64 & 16 & 36,36 & 6 & 23,08 & 20 & 76,92 \\
\hline 9 & $\begin{array}{l}\text { There are no any residual materials on the } \\
\text { net. }\end{array}$ & 31 & 70,45 & 13 & 29,55 & 16 & 61,54 & 10 & 38,46 \\
\hline 10 & Are the anchor points intact? & 40 & 90,91 & 4 & 9,09 & 20 & 76,92 & 6 & 23,08 \\
\hline 11 & $\begin{array}{l}\text { Have the nets been tested for the effects of } \\
\text { UV rays in the last } 12 \text { months of work and } \\
\text { have a valid ID and current test label? }\end{array}$ & 24 & 54,55 & 20 & 45,45 & 7 & 26,92 & 19 & 73,08 \\
\hline 12 & $\begin{array}{l}\text { Are the nets reasonably mounted on the } \\
\text { underside of the work platform? }\end{array}$ & 41 & 93,18 & 3 & 6,82 & 4 & 15,38 & 22 & 84,62 \\
\hline 13 & $\begin{array}{l}\text { The gap between the net and the building is } \\
\text { less than } 100 \mathrm{~mm} \text {. }\end{array}$ & 38 & 86,36 & 6 & 13,64 & 19 & 73,08 & 7 & 26,92 \\
\hline 14 & $\begin{array}{l}\text { Are all nets tied to the system and anchor } \\
\text { points properly? }\end{array}$ & 38 & 86,36 & 6 & 13,64 & 9 & 34,62 & 17 & 65,38 \\
\hline 15 & $\begin{array}{l}\text { There are no obstacles less than } 3 \text { meters } \\
\text { below the safety net area. }\end{array}$ & 36 & 81,82 & 8 & 18,18 & 5 & 19,23 & 21 & 80,77 \\
\hline
\end{tabular}

- It has been observed that; no deformation in nets, tie ropes or supporting frame, the ropes are well tied, anchorage points are intact and installation of the work platform was done properly in Turkey. However, there were some deformations in safety nets in many sites. The safety nets were placed on the metal grid and the materials were not sufficiently flexible and nets were deformed in Iran. It was also determined that the cover/linens was used in some construction sites and the covers were unqualified cloths were not in compliance with the standards.
- There were no obstacles under the safety net in Turkey. On the other hand the standards were not followed in Iran. It was determined that the bearing structure placed under the safety net consists of a very frequently metal grid and there is no ability to absorb the effect the worker will be exposed to at the time of the fall in Iran. Workers face the danger of death by crashing.

- In about one-third of Turkey, nets were not clean. There were residual materials on the net. But in Iran, mostly it was found clean.

The maximum permissible fall height is 6 meters according to TS EN 1263 - 2 standard. 
Observations show that the distance between the safety nets and the work platform is more than 6 meters and nets are not leveled up in parallel with the construction level.

Especially in Iran construction sites, it is seen that safety net applications have damaged and have no continuity throughout the facade. Safety net applications should be continiued throughout the facade. Different safety measures should be considered where safety net cannot be established due to working conditions or building facade.

\section{Discussion}

Studies on occupational accidents and occupational diseases have shown that there is an inverse relationship between fatal occupational accidents and human development index, and that fatal occupational accidents are higher in countries with low human development index [6,34-36]. Most fatal accidents in construction work are caused by falling from a height. Safety precautions must be taken properly to prevent or reduce the impact of accidents. The proper application of the measures depends on the safety awareness of project managers and top management and safety regulations of industry [17,37]. This paper discussed safety net applications in Turkey and Iran. In Turkey, with national safety net standard named TS EN 1263, it is seen that user manual and labels are kept in most sites. By contrast, in Iran, user manual and labels are kept in few sites. It is obvious that existence of national standards is very important for proper system application. The level of detail in the standards affects detail of safety net practices. Furthermore, safety culture and workers' perspective on occupational health and safety are vital factors for proper application. The results show that existence of detailed national regulations and standards are influencial on proper application of safety nets. User manual and safety net label are important for proper usage of nets. While the labels and user manual found in the most sites in Turkey, it is not found in Iranian sites.

Another vital factor for proper usage of safety nets is testing. In order to ensure continuity of protection, safety nets should be tested on fall accidents. Pre-testing the effectiveness of the net provides insight into how successful it will be in the event of an accident. Manufacturers should provide the test mesh in order to test the net's durability. Besides, nets should be tested for the effects of UV rays. These are also requirements of TS EN 1263 standard. It seems that test procedure does not applicated in half of sites in Turkey and most sites in Iran. Testing the collective protection measures is closely related to the safety culture of the contractor and the country. The findings and observations on the construction sites show that the safety culture and climate have not yet reached the expected level in both countries. Small and medium sized contractors regard occupational safety measures as an additional budget and costincreasing factor.

Literature findings show that in countries with low human development index, there is greater lack of social protection in the pre- and postoccupational accidents and diseases [38,39]. In this study, not only the deficiencies in the implementation of safety networks, but also the approaches of countries to occupational safety practices are investigated. In Turkey, it was shown that safety nets were installed by the relevant official regulations, however, the sustainability of the nets (periodic control of the nets, cleaning residual materials and levelling up the netting in parallel with the progress of the building etc.) was not given importance during the construction process. On the other hand, it has seen that the materials used in safety net applications do not meet the standards and proper installation requirements in Iran. As a result of the observations, it is seen that all stakeholders have duties to establish, adopt and implement the occupational safety culture in the countries. It is necessary for creating a culture of occupational safety, firstly, the governments should enact legal regulations on detailed OHS and social protection, including necessary deterrent penalties, and prepare standards for OHS practices. All stakeholders should be informed through professional chambers and local authorities. 
Studies show that the most important factor in occupational accidents in the construction sector is the lack of supervision [40]. As a result of the observations, it is seen that there is a lack of supervision in both countries. Project managers and site supervisors do not audit OHS applications especially during the production. Workers need to be supported with trainings in order to gain a safety culture. The aim is to raise employee awareness. The trainings should aim three main gains. Firstly; aware of his/her legal rights (legislation) and requesting $\mathrm{OHS}$ measures from the contractor; secondly, how to use OHS equipment; and thirdly, understanding the vital importance of OHS and not to show psychological resistance during the application of OHS measures.

The level of education of the construction site employees undoubtedly affects the level of consciousness. The uneducated workers in developing countries or underdeveloped countries leads to fatalistic approach. It is obvious that OHS trainings should be given importance. Activities that increase awareness regarding working at height are very important factors that reduce work accidents [41].

\section{Conclusions}

In order to examine the safety net applications used in high-rise building sites, safety net checklists have been filled in Turkey and Iran sites. In both countries, there are some shortcomings in all construction sites. Deficiencies related to the user manual or information labels are important, but they do not reduce the effectiveness of safety nets. Deformations in the nets, mounting faults, residual materials on the net, more than $10 \mathrm{~cm}$ gap between net and the construction, and distance less than 3 meters below the net can prevent the fulfillment of the function of safety net. It has determined that there are construction sites where only one cover/linoleum is used instead of the net especially in Iran. The following are the main topics to be considered regarding safety net practices:

- Safety nets should be preferred in compliance with the project and the standards.
- Safety nets should be installed and disassembled by an expert team.

- Periodic inspection and maintenance of safety nets should be followed by experts.

- In case of any deformation, the nets should be replaced immediately.

- Safety nets should be kept clean.

- In the production progresses, safety nets should be levelled up in parallel with the construction speed.

Turkey has made improvements in regulations by examining international legislation and standards in recent years. Increasing OHS audits aimed to create a sustainable safety culture among all stakeholders. The establishment of a sustainable safety culture will undoubtedly involve a period of time. It is recommended that the Iranian government and interested parties should benchmark improve the regulations by examining the practices in developed countries.

The study has some limitations. First, the research includes only small and medium sized enterprises and sampling was determined randomly. Therefore, implications are not covering whole industry. It is thought to be beneficial that observation studies to be carried out by increasing the number of samples. The second limitation of the study is content of the checklist. Checklist can be developed and more comprehensive by complying with changing standards and legal regulations. In addition, information technologies can be developed to facilitate the tracking of such equipment in future studies.

\section{Declaration of conflicting interests}

The author(s) declared no potential conflicts of interest with respect to the research, authorship, and/or publication of this article.

\section{References}

[1] Eurostat. Accidents at work statistics [Internet]. 2018 [cited 2021 Feb 26]. Available from: https://ec.europa.eu/eurostat/statisticsexplained/index.php?title=Accidents_at_work_stat istics\#Analysis_by_activity 
[2] AÇSHB. Türkiye'nin İSG Görünümü [Internet]. 2021 [cited 2021 Feb 26]. Available from: https://www.detam.com.tr/wpcontent/uploads/2020/10/IstatistiklerleTurkiyenin-ISG-Gorunumu.pdf

[3] Mohammadi A, Tavakolan M, Khosravi Y (2018) Factors influencing safety performance on construction projects: A review. Safety Science; 109: 382-97.

[4] Wong L, Wang Y, Law T, Lo CT. (2016) Association of root causes in fatal fall-from-height construction accidents in Hong Kong. Journal of Construction Engineering and Management, 142(7): 04016018.

[5] Hämäläinen P, Takala J, Saarela KL (2006) Global estimates of occupational accidents. Safety Science, 44(2): 137-56.

[6] Karadeniz O (2012) Dünya'da ve Türkiye'de iş kazaları ve meslek hastalıkları ve sosyal koruma yetersizliği. Çalışma ve Toplum, (3): 15-75.

[7] Bilir S, Gürcanlı GE (2018) A method for determination of accident probability in construction industry. Teknik Dergi, 29(4): 853761.

[8] Gürcanlı GE, Müngen U (2013) Analysis of construction accidents in turkey and responsible parties. Industrial Health, 51(6): 581-95.

[9] Hide S, Haslam R, Gibb A, Gyi D, Atkinson S, Pavitt T, et al. Causal Factors in Construction Accidents. Research Report, Loughborough University, 2003.

[10] Müngen MU (2011) İnşaat sektörümüzdeki başlica iş kazası tipleri. Türkiye Mühendislik Haberleri, 469(5): 32-9.

[11] Guo BHW, Goh YM (2017) Ontology for design of active fall protection systems. Automation in Construction, 82: 138-53.

[12] Winge S, Albrechtsen E (2018) Accident types and barrier failures in the construction industry. Safety Science, 105: 158-66.

[13] Umer W, Li H, Lu W, Szeto GPY, Wong AYL (2018) Development of a tool to monitor static balance of construction workers for proactive fall safety management. Automation in Construction, 94: 438-48.

[14] Yılmaz GK, Başağa HB (2018) Assessment of occupational accidents in construction sector: A case study in Turkey. Journal of Construction Engineering, Management \& Innovation, 1(2): 95107.
[15] Akboğa Kale Ö, Baradan S (2020) Identifying factors that contribute to severity of construction injuries using logistic regression model. Teknik Dergi, 31(2): 9919-40.

[16] Baradan S, Akboğa Ö, Çetinkaya U, Usmen MA (2016) Ege bölgesindeki inşaat iş kazalarının sıklık ve çapraz tablolama analizleri. Teknik Dergi, 27(1): 7345-70.

[17] Nadhim E, Hon C, Xia B, Stewart I, Fang D (2016) Falls from height in the construction industry: a critical review of the scientific literature. International Journal of Environmental Research and Public Health, 13(7): 638.

[18] Khodabandeh F, Kabir-Mokamelkhah E, Kahani M (2016) Factors associated with the severity of fatal accidents in construction workers. Medical Journal of the Islamic Republic of Iran, 30: 469.

[19] Janicak CA (1998) Fall-related deaths in the construction industry. Journal of Safety Research, 29(1): 35-42.

[20] Chi C-F, Chang T-C, Ting H-I (2005) Accident patterns and prevention measures for fatal occupational falls in the construction industry. Applied Ergonomics, 36(4): 391-400.

[21] Gurcanli GE, Bilir S, Sevim M (2015) Activity based risk assessment and safety cost estimation for residential building construction projects. Safety Science, 80: 1-12.

[22] Adam JM, Pallarés FJ, Calderón PA (2009) Falls from height during the floor slab formwork of buildings: Current situation in Spain. Journal of Safety Research, 40(4): 293-299.

[23] Unsar S, Sut N (2009) General assessment of the occupational accidents that occurred in Turkey between the years 2000 and 2005. Safety Sciences, 47(5): 614-619.

[24] Amiri M, Ardeshir A, Zarandi Fazel MH (2014) Risk-based analysis of construction accidents in Iran during 2007-2011 meta analyze study. Iranian Journal of Public Health, 43(4): 507-522.

[25] Mehrdad R, Seifmanesh S, Chavoshi F, Aminian O, Izadi N (2014) Epidemiology of occupational accidents in Iran based on social security organization database. Iranian Red Crescent Medical Journal, 16(1): e10359.

[26] Huang X, Hinze J (2003) Analysis of construction worker fall accidents. Journal of Construction Engineering and Management, 129(3): 262-271.

[27] Kines P (2002) Construction workers' falls through roofs: Fatal versus serious injuries. Journal of Safety Research, 33(2): 195-208. 
[28] Guo BH., Goh YM, Scheepbouwer E, Zou Y. An ontology of control measures for fall from height in the construction industry. 35th International Symposium on Automation and Robotics in Construction, 2018, Berlin, Germany.

[29] Dong XS, Largay JA, Choi SD, Wang X, Cain CT, Romano N (2017) Fatal falls and PFAS use in the construction industry: Findings from the NIOSH FACE reports. Accident Analysis of Prevention, 102: $136-43$.

[30] AÇSHB. Güvenlik Aği ile Çalişmalarda İş Sağlığ 1 ve Güvenliği. 2018.

[31] Peşan S. Yap1 İşlerinde Yüksekten Düşmeyi Önleme Sistemleri. ÇSGB İş Tefitş Kurulu Başkanlığı, 2011.

[32] Uzun M, Yaman S. İnşaatlarda kullanılan TS EN 1263-1 ve 1263-2 standartlarına uyumlu güvenlik ağlarının özellikleri. 5 İşçi Sağlığı ve İş Güvenliği Sempozyumu, 2015, İzmir, Turkiye.

[33] Dursun AF. Yüksekte Çalışmada Güvenlik Ağları. İş Güvenliği Uzmanlık Tezi, ÇSGB İş Sağlığı ve Güvenliği Genel Müdürlüğü, 2016.

[34] Hämäläinen P, Saarela LK, Takala J (2009) Global trend according to estimated number of occupational accidents and fatal work-related diseases at region and country level. Journal of Safety Research, 40(2): 125-139.
[35] Türen U, Gökmen Y, Bayram N. Do national human development levels and ICT diffusion curtail fatal occupational injuries? Panel data of OECD. Sydney International Conference Proceedings of Australian Society for Commerce Industry and Engineering (SCIE), 2014.

[36] Taner MT, Mıhcı H, Sezen B, Kağan G (2015) A comparative study between human development index and work accidents in Turkey and the EU member countries. Journal of Research in Business, Economics and Management, 4(1): 274-288.

[37] Tam CM, Zeng SX, Deng ZM (2004) Identifying elements of poor construction safety management in China. Safety Science, 42(7): 569-586.

[38] Reynaud E (2006) Social security for all: global trends and challenges. The Comparative Labor Law and Policy Journal, 27: 123-150.

[39] Kwesi A-T, Kwasi D-B (2011) Occupational health and safety: key issues and concerns in Ghana. International Journal of Business and Social Science, 2(14): 119-126.

[40] Sadeghi F, Bahrami A, Fatemi F (2014) The effects of prioritize inspections on occupational health hazards control in workplaces in Iran. Journal of Research in Health Sciences, 14(4): 282-286.

[41] Bunting J, Branche C, Trahan C, Goldenhar L (2017) A national safety stand-down to reduce construction worker falls. Journal of Safety Research, 60: 103-111. 